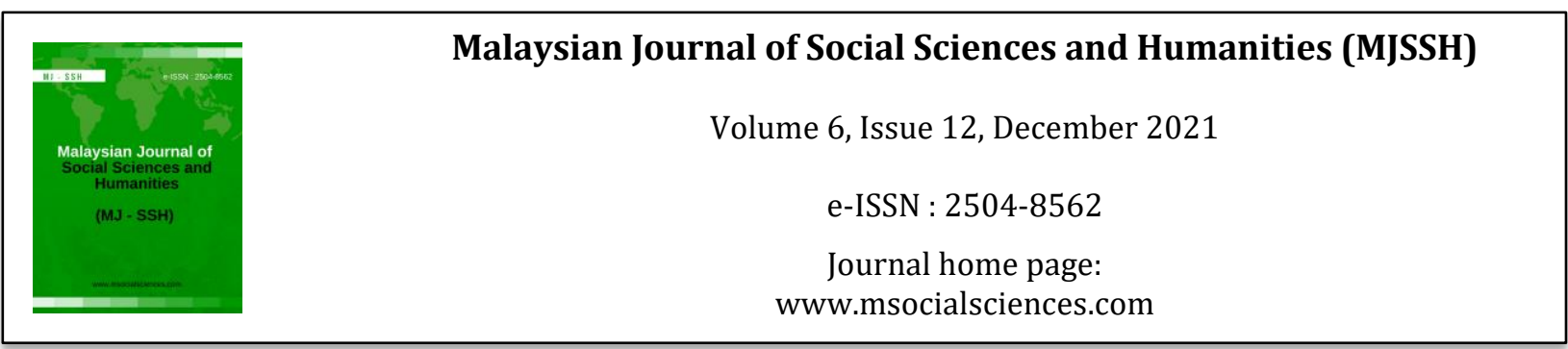

\title{
Dokumentasi Tumbuhan Ubatan Mengikut Kearifan Tempatan Wanita Bugis di Pulau Sebatik, Sabah, Malaysia
}

\author{
Suriyanah Laudeh' ${ }^{1}$, Jurry Foo ${ }^{1}$ \\ 1Fakulti Sains Sosial dan Kemanusiaan, Universiti Malaysia Sabah (UMS), \\ Jalan UMS, 88400 Kota Kinabalu, Sabah, Malaysia \\ Correspondence: Suriyanah Laude (ana_suriyanah@yahoo.com.my)
}

\begin{abstract}
Abstrak
Artikel ini menghuraikan penggunaan tumbuhan ubatan dalam kalangan wanita Bugis di Pulau Sebatik, Sabah, Malaysia berdasarkan kearifah tempatan. Tinjauan awal mendapati masyarakat Bugis masih mengamalkan tumbuhan untuk kesihatan. Oleh itu kajian dijalankan di Kampung Aji Kuning Sebatik untuk mendokumentasikan sespesies tumbuhan yang sering digunakan kaum wanita Bugis, termasuk kegunaan dan penggunaannya. Data dikumpulkan melalui pemerhatian dan kajian kepustakaan. Hasil kajian merekodkan 18 spesies tumbuhan daripada 18 famili digunakan dengan kerap di kawasan kajian. Kajian ini penting bagi memahami kepentingan tumbuhan kepada manusia dari segi kesihatan.
\end{abstract}

Kata kunci: kearifan tempatan, Bugis, penggunaan, ubat

\section{Documentation of Medicinal Plants Based on the Local Wisdom of Bugis Women ins Sebatik Island, Sabah, Malaysia}

\begin{abstract}
This article aims to describe the uses of medicinal plants by the Bugis women in Kampung Aji Kuning based on their local wisdom. A preliminary survey found that the Bugis society still using plants for health. Hence this study managed to be documented the species and it uses among the Bugis women including the information of the uses as well as its usage. Data was collected via observation and literature revie. Result of the study recorded 18 plants species that were used frequently in the study area. This study is important to understand the importance of plants in human health.
\end{abstract}

Keywords: local wisdom, Bugis, uses, medicine

\section{Pengenalan}

Kebergantungan manusia terhadap tumbuhan adalah satu proses interaksi dalam sistem biosfera. Penggunaan tumbuhan adalah amalan budaya yang menjadi kearifan tempatan setiap masyarakat, sama ada ia diwarisi ataupun dipelajari daripada masyarakat lain dalam satu tempoh masa tertentu. Tinjauan awal di Kampung Aji Kuning, Sebatik mendapati bahawa amalan menggunakan tumbuhan sebagai ubat masih di popular dalam kalangan wanita Bugis di Kampung Aji Kuning atas faktor amalan berterusan, 
kaedah penggunaan dan akses. Kajian Andi Nurela (2012) masyarakat di kampung Aji Kuning lebih cenderung kepada perubatan tradisional dengan meminta rawatan dukun di kampung. Oleh itu artikel ini bertujuan untuk menghuraikan penggunaan tumbuhan ubatan yang telah dikenal pasti sebagai ubat dalam kalangan wanita Bugis di kawasan kajian.

\section{Sorotan Literatur}

Kearifan tempatan merujuk kepada pengetahuan sesuatu kumpulan manusia yang menjalani kehidupan bersama sebagai masyarakat. Ia berkaitan dengan pandangan hidup, ilmu pengetahuan, kebijaksanaan, nilai bak dan pelbagai strategi manusia dalam memenuhi keperluan hidup (Jacinta \& Asmiaty, 2020). Nilai kearifan tempatan adalah seperti berdoa memohon pertolongan dan perlindungan daripada Tuhan, menjaga keharmonian kehidupan manusia dengan alam, bekerja bersungguh-sungguh, memupuk keberanian dalam kehidupan, saling membantu sesama manusia, selalu menepati janji dan melestarikan tradisi leluhur (Minah, 2019). Pengetahuan yang diwarisi dan dipelajari digunakan untuk menguruskan sumber kehidupan bagi manusia (Jurry, 2017). Malah pengetahuan tersebut juga dijadikan sebaga garis panduan kepada aktiviti harian manusia dalam hubungan mereka dengan keluarga, jiran, penduduk kampung dan persekitaran (Normadiah \& Low, 2015).

Taburan masyarakat Bugis meluas hingga ke seluruh Nusantara dan nama "Bugis" berasal dari kata "to ugi' yang bermaksud orang Bugis (Andi Nurela, 2012). Kajian kepustakaan dan tinjauan awal di lapangan menunjukkan kearifan tempatan menggunakan tumbuhan dalam sistem kesihatan bagi masyarakat Bugis didapati diperolehi daripada amalan yang diwarisi dan yang dipelajari daripada orang lain. Masyarakat Bugis Makassar misalnya masih memegang teguh terhadap pengetahuan mengenai ubatan tradisional sebagai sebahagian daripada sistem budaya (Dloyana, 2017). Penulisan lain mengenai perubatan masyarakat Bugis hanya didokumentasikan dalam bentuk penulisan perkongsian atas talian.

\section{Metod Kajian}

Kajian ini menggunakan kaedah pemerhatian dan temu bual mendalam bagi mengenal pasti penggunaan tumbuhan ubatan dalam kalangan wanita Bugis di Sebatik. Pulau Sebatik adalah suatu daerah yang berada di sempadan antara negara Indonesia dengan negara Malaysia di mana pulau ini dimiliki oleh dua negara, iaitu Sebatik bagian utara merupakan milik Malaysia dan bagian selatan adalah milik Indonesia (Robert, 2012). Penduduknya majoriti berketurunan Bugis dari pelbagai sub etnik dan lazimnya mempunyai perkaitan kekeluargaan di antara satu komuniti dengan komuniti lain dalam pulau tersebut.

Maklumat kajian diperolehi melalui kaedah temu bual mendalam bagi mendapatkan respons pengguna dan pengamal perubatan berasaskan tumbuhan dicatat dan seterusnya dianalisis secara deskriptif. Temubual mendalam tersebut dijalankan selama dua minggu di kawasan kajian dengan menggunakan soalan terbuka melalui dua kali lawatan.

Pemerhatian turut serta pula dilakukan bagi tujuan mendapatkan maklumat tentang cara dan kaedah penggunaan tumbuhan ubatan yang biasa digunakan oleh masyarakat di kawasan kajian. Proses pemerhatian ini dijalankan dengan menyertai aktiviti merawat yang dilakukan oleh in pengamal perubatan di kawasan kajian. Manakala bahan rujukan hasil kajian lepas pula dirujuk bagi memahami isu berkaitan tumbuhan ubatan dan mendapatkan data sokongan yang boleh membantu kajian ini.

Kawasan kajian tertumpu kepada kawasan Kampung Aji Kuning di Pulau Sebatik (rujuk Rajah 1). Pemilihan kawasan kajian ini adalah berdasarkan kepada tadbiran populasi komuniti Bugis yang tinggi di kampung tersebut dan keunikan lokasinya yang terletak di sempadan antara dua negara iaitu Malaysia dan Indonesia. 


\section{Rajah 1: Kawasan kajian: Kampung Aji Kuning, Sebatik}

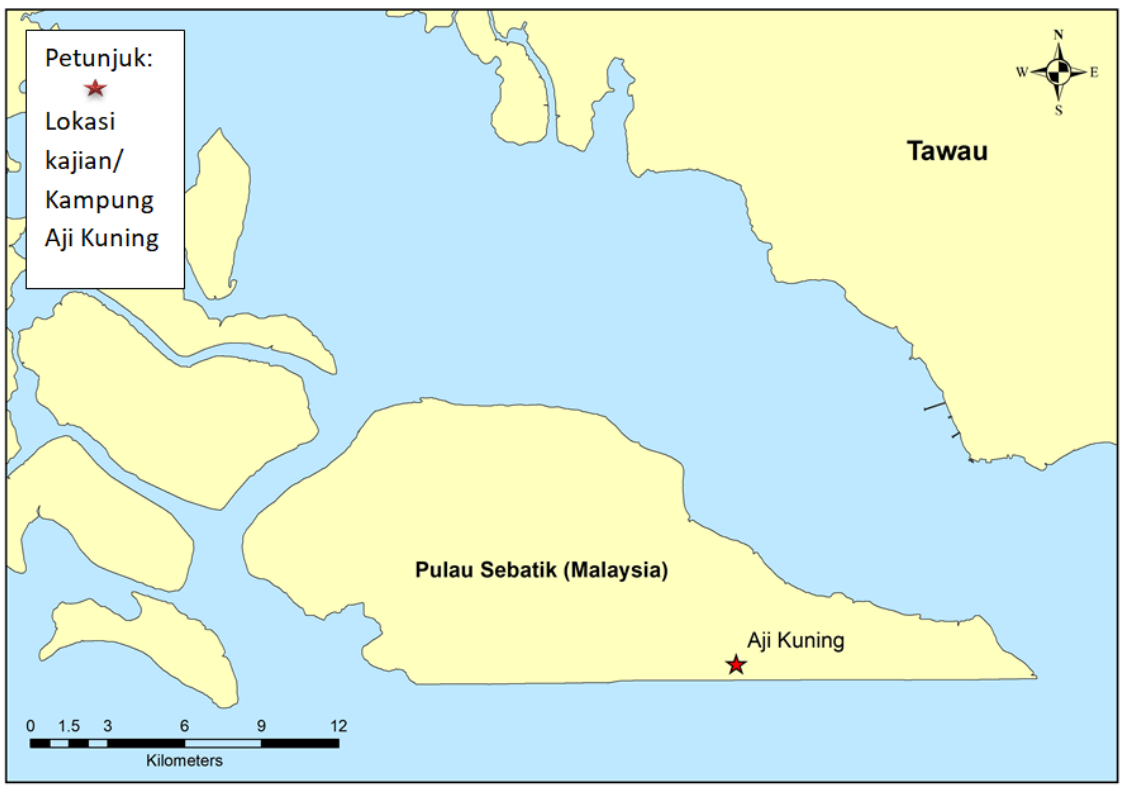

Sumber: Suriyanah \& Jurry (2019)

\section{Hasil Kajian}

Hasil kajian di Kampung Aji Kuning merekodkan sebanyak 18 spesies tumbuhan daripada 16 famili yang telah dikenal pasti bernilai untuk kesihatan (Jadual 1). Maklumat kegunaan dan penggunaan tumbuhan ubatan dihuraikan dalam artikel ini adalah berdasarkan maklumat yang diperolehi daripada informan di Kampung Aji Kuning. Spesies tumbuhan dijelaskan mengikut nama botani, nama tempatan dan famili. Kemudian huraian disertai dengan kegunaan dan cara penggunaan tumbuhan ubatan berdasarkan hasil kajian temu bual mendalam dan pemerhatian yang dilakukan.

Jadual 1: Tumbuhan ubatan masyarakat Bugis di Kampug Aji Kuning

\begin{tabular}{|c|c|c|c|c|}
\hline Bil & $\begin{array}{c}\text { Nama } \\
\text { Tumbuhan }\end{array}$ & $\begin{array}{l}\text { Nama } \\
\text { Bugis }\end{array}$ & Nama botani & Famili \\
\hline 1. & $\begin{array}{l}\text { Rumput mutiara/ } \\
\text { Siku-siku/ Asam } \\
\text { susur }\end{array}$ & Daung canggadori & Sida rhombifolia & Malvaceae \\
\hline 2. & Kunyit & Onyik & Curcuma domestica & Zingiberaceae \\
\hline 3. & Daun galenggang & Daung galingkan & Senna alata & Fabaceae \\
\hline 4. & Lidah buaya & Lilla buaja & Aloe vera & Liliaceae \\
\hline 5. & Bawang merah & Lasuna cellak & Allium cepa & Alliaceae \\
\hline 6. & Bawang putih & Lasuna puteh & Allium sativum & Alliaceae \\
\hline 7. & Buah kelapa & Kaluku & Cocos nucifera & Arecaceae \\
\hline 8. & Labu & Lawo & Sechium edule & Cucurbitaceae \\
\hline 9. & Buah mengkudu & Baja’ & Morinda citrifolia & Rubiaceae \\
\hline 10. & Daun ubi & Daung lamey & Manihot esculenta & Euphorbiaceae \\
\hline 11. & Daun pisang & Daung loka & Musa paradisiaca & Musaceae \\
\hline 12. & Daun sup & Daung sup & Apium graveolens & Umbilliferae \\
\hline 13. & $\begin{array}{l}\text { Daun gemunggal/ } \\
\text { kelor }\end{array}$ & Daung kelor & Moringa oleifera & Moringaceae \\
\hline 14. & Daun jambu & Daung jampu & Psidium guava & Myrtaceae \\
\hline 15. & Kayu jawa & Aju Jawa & $\begin{array}{l}\text { Lannea } \\
\text { coromandelica }\end{array}$ & Sapindalaceae \\
\hline
\end{tabular}


DOI: https://doi.org/10.47405/mjssh.v6i12.1200

\begin{tabular}{lllll} 
16. & Mas cotek & Mas cotek & Ficus deltoide & Moracae \\
17. & Daun papaya & $\begin{array}{l}\text { Daung pellek } \\
\text { keniki }\end{array}$ & Dolonaceae \\
18. & $\begin{array}{l}\text { Daun tangan- } \\
\text { tangan }\end{array}$ & Daung pai' pai' & Jatropha curcas & Euphorbiaceae \\
\hline
\end{tabular}

\section{Sida rhombifolia / Malvaceae (Rumput mutiara/ Siku-siku/ Asam susur)}

Sida rhombifolia digunakan untuk melawaskan proses pembuang air besar, menyembuhkan demam, mengurangkan sakit-sakit badan, menjaga kesihatan mata dan mencantikkan kulit bagi kaum wanita. Kaedah penggunaan ialah pengambilan secara oral iaitu diminum. Manakala dari segi penyediaan pula semua bahagian rumput dibersihkan lalu direbus sehingga mendidih dan sedia untuk diminum apabila rebusan tadi menjadi suam.

\section{Curcuma domestica / Balsaminaceae (Kunyit)}

Curcuma domestica digunakan untuk menyembuhkan penyakit cacar, merawat masalah kulit dan bagi pelbagai tujuan kecantikan. Ia juga berguna untuk mengurangkan demam, serangan selesema dan batuk berkahak. Cara penggunaannya ialah secara pengambilan oral iaitu dikunyah. Cara penyediaannya pula ialah setelah kunyit hidup dibersihkan maka setengah $\mathrm{cm}$ daripada bahagiannya dikunyah bersama satu biji lada putih. Amalan ini perlu dilakukan secara berterusan selama tujuh hari berturut-turut.

\section{Senna alata / Leguminosae (Daun galenggang)}

Senna alata dikenali juga sebagai Gelenggang digunakan untuk menghilangkan panau dan menghaluskan kulit. Ia juga digunakan bagi tujuan kecantikan kulit. Untuk menggunakannya daun direbus lalu diminum apabila rebusan telah suam. Bagi penyakit berkaitan kulit pula air rebusan disapukan pada bahagian yang bermasalah.

\section{Aloe vera / Liliaceae (Lidah buaya)}

Aloe vera mengurangkan masalah kelemumur dan merawat kulit wajah yang bermasalah. Ia juga digunakan untuk menyembuhkan luka luaran. Kaedah penyediaannya ialah dengan mengambil lendir lidah buaya lalu digunakan dengan cara disapu pada bahagian kulit yang bermasalah.

\section{Allium cepa / Alliaceae (Bawang merah)}

Allium cepa merawat masalah kulit termasuk jerawat, bisul, gatal pada kulit dan cacar. Ia juga digunakan untuk merawat masalah demam. Tumbuhan ini juga mengurangkan sakit beguk dan kanser. Cara penyediaannya ialah dengan membersihkan dan meramas bawang tersebut lalu dicampurkan dengan air kelapa. Bahan campuran tersebut kemudiannya disapu pada bahagian badan yang bermasalah.

\section{Allium sativum / Liliaceae (Bawang putih)}

Allium sativum terkenal dengan kegunaan menyembuhkan masalah demam. Cara penyediaannya ialah bawang putih dicampurkan dengan minyak kelapa. Lalu campuran tersebut disapukan pada seluruh anggota badan dengan cara mengurut yang santai.

\section{Cocos nucifera / Arecaceae (Kelapa)}

Cocos nucifera digunakan untuk membuang racun dalam badan, merawat sakit beguk, sakit kepala, mengurangkan gatal-gatal badan dan untuk tujuan kecantikan. Ia juga digunakan untuk menyembuhkan penyakit kerumut, kanser, jerawat, demam dan menyembuhkan penyakit cacar. Penyediaan ubat untuk masalah kulit seperti gatal-gatal, kerumut, jerawat, cacar dan sakit beguk, air kelapa disatukan bersama 
bawang merah yang telah diramas. Bahan tersebut kemudiannya disapukan pada bahagian kulit yang bermasalah seberapa kerap yang mungkin. Apabila kulit mula kering, air kelapa dan bawang merah tadi disapukan semula pada bahagian kulit agar kulit sentiasa lembap. Manakala bagi masalah keracunan pula, merawat sakit kepala, mencantikkan kulit dari dalam dan luar digalakkan mengamalkan meminum air kelapa muda setiap hari.

\section{Sechium edule / Cucurbitaceae (Labu)}

Sechium edule dapat mengurangkan dan meredakan penyakit asma. Cara penyediaannya ialah bersihkan daun labu yang muda lalu dihancurkan sehingga lumat. Air daripada daun tersebut disaring untuk diminum (anggaran kuantiti pengambilan kira-kira 1 sudu kecil).

\section{Morinda citrifolia / Rubiaceae (Mengkudu)}

Morinda citrifolia menghitamkan rambut yang beruban dan merawat rambut gugur. Cara penyediaannya ialah dengan merebus daunnya lalu diminum. Manakala untuk tujuan merawat darah tinggi dan memperbaiki kitaran haid serta keputihan, buahnya dimakan dengan anggaran satu biji untuk seminggu.

\section{Manihot esculenta / Euphorbiaceae (Ubi)}

Manihot esculenta digunakan untuk menambah darah bagi wanita yang mengalami masalah kurang darah terutamanya bagi ibu mengandung. Kaedah penyediaannya ialah dengan menumis daunnya atau diambil seperti ulam.

\section{Musa paradisiaca / Musaceae (Pisang)}

Beberapa kegunaan Musa paradisiaca ialah untuk kecantikan kulit wajah, mengurangkan demam panas dan mengurangkan masalah sakit tekak. Cara penyediaannya ialah dengan merebus segenggam daunnya, ditapis lalu diminum. Ini diamalkan dengan kerap untuk kecantikan kulit wajah, manakala untuk demam dan masalah sakit tekak diminum semasa simptom penyakit tersebut timbul.

\section{Apium graveolens / Umbilliferae (Daun sup)}

Apium graveolens sering digunakan untuk mengurangkan masalah penyakit gout yang dipanggil sebagai penyakit reumatik oleh wanita etnik Bugis di Sebatik. Cara penggunaannya ialah dengan menumis daunnya atau dimakan sebagai ulam.

\section{Moringa oleifera / Moringaceae (Gemunggal/ kelor)}

Moringa oleifera sangat popukar kebelakanan ini rentetan daripada penemuan khasiatnya sebagai ubat. Namun dalam kalangan masyarakat Bugis, ia sudah lama dijadikan makanan dan diamalkan dalam sistem kesihatan. Bagi tujuan kesihatan. Moringa oleifera digunakan untuk tujuan mencantikkan kulit wanita serta mengatasi masalah 'usus buntu' iaitu masalah berkaitan usus. Daun yang sudah dimasak atau ditumis, dimakan disertakan dengan selawat.

\section{Psidium guava / Myrtaceae (Jambu)}

Psidium guava sememangnya terkenal dengan khasiat vitaminnya. Menyembuhkan dan mengurangkan masalah cirit birit. Daun jambu direbus dan setelah suam, boleh diminum dan dimakan bersama daunnya (1 kali untuk sehari).

\section{Lannea coromandelica / Sapindalaceae (Kayu jawa)}

Lannea coromandelica menyembuhkan luka luar pada kulit seperti bisul. Bahan dari dalam batang kayu yang dikikis diletakkan pada bahagian keliling luka secara membulat tanpa menutupi bahagian mata 
luka bagi membenarkan nanah mengalir keluar. Ini akan mengeringkan dan seterusnya menyembuhkan luka setelah nanah berjaya dikeluarkan.

\section{Ficus deltoide / Moraceae (Mas cotek)}

Ficus deltoide mengurangkan masalah kulit gatal. Daunnya diambil sebanyak segenggam lalu direbus bersama satu air botol besar. Air rebusan diminum dan perlu dihabiskan dalam tempoh tujuh hari. Setiap kali ingin minum air tersebut perlu dipanaskan semula, dibiarkan suam dahulu baharulah diminum.

\section{Carica papaya / Solonaceae (Papaya/ betik)}

Digunakan untuk menangani masalah gaut dan penyakit kencing manis. Bagi sakit gaut, buah papaya muda direbus bersama kulit. Setelah air mendidih, tunggu sehingga sejuk lalu diminum bersama air kelapa. Penyediaannya untuk merawat penyakit kencing manis pula iala dengan memilih daun papaya muda bersaiz kecil sebanyak tujuh helai, lalu dicampuri dengan tiga sudu madu dan satu biji kuning telur. Semua bahan tersebut dikisar sehingga sebati lalu diminum.

\section{Jatropha curcas / Euphorbiaceae (Daun tangan-tangan)}

Jatropha curcas ialah tumbuhan yang digunakan untuk menyembuhkan buasir. Daun tangan-tangan dilayur di atas api atau dipanaskan dalam kuali. Selesai dilayur, tekap pada buntut. Manakala untuk mengurangkan masalah sawan dan ampus, beberapa helai daun tangan-tangan dicampurkan bersama sarang anai, beras sebanyak tujuh butir dan satu ulas bawang putih dan bawang merah, begitu juga kapur (yang boleh dimakan) dan limau nipis. Kesemua campuran tersebut dipanaskan dengan cara menggoreng tanpa minyak dalam kira-kira lima minit. Kemudian campuran tersebut diletakkan di bahagian dahi, dada dan leher.

\section{Perbincangan Kajian}

Kegunaan tumbuhan ubatan dalam kalangan wanita Bugis kebanyakannya tertumpu kepada rawatan dan penjagaan bahagian kulit dan merawat penyakit biasa seperti demam panas dan sebahagian kecilnya dilihat merawat penyakit lebih berat seperti kencing manis. Mereka yakin bahawa tumbuhan adalah lebih berkesan berbanding dengan perubatan moden.

Dari segi penggunaan tumbuhan ubatan pula banyak bahagian tumbuhan yang digunakan adalah bahagian daun. Manakala hampir kesemua spesies disediakan secara merebus dengan mencampurkan tumbuhan tersebut dengan beberapa bahan lain seperti beras, air kelapa dan madu. Pengambilan ubatan pula hampir semuanya diminum, selain daripada disapu dan dimakan mentah. Ada daripadanya pula diambil dengan bacaan selawat. Ini menunjukkan amalan penggunaan yang mudah dilakukan. Pengambilan ubat sambil selawat pula menunjukkan pengaruh agama Islam dalam budaya masyarakat Bugis di kawasan kajian.

Faktor kelangsungan amalan penggunaan tumbuhan dalam kalangan wanita Bugis di kawasan kajian dipengaruhi tiga faktor, iaitu kerana ia adalah amalan berterusan dan kaedah penggunaannya amat mudah, selain daripada itu sumber tumbuhan ubatan sangat mudah diakses sama ada dari sekitar tempat tinggal mahupun dari pasar. Manakala harga mampu milik juga menjadi punca utama mereka memilih untuk terus menggunakan tumbuhan sebagai ubat. Kajian ini seperti dapatan Jurry et al. (2014) dan Kanta Kumari et a. (1998). yang mendapati harga mampu milik tumbuhan ubatan adalah satu daripada faktor menyebabkan perubatan tradisional terus diamalkan.

Amalan dan kaedah penggunaan merujuk kepada kekerapan menggunakan tumbuhan sebagai ubat. Hampir setiap hari kaum wanita Bugis di Kamung Aji Kuning menggunakan tumbuhan, khususnya bagi tujuan kesihatan. Kecenderungan infoman menunjukkan masyarakat di Kampung Aji Kuning lebih 
kepada penggunaan ubatan alternatif berbanding mendapatkan rawatan di hospital. Selain itu harga sumber pula sangat murah dan mampu milik.

\section{Kesimpulan}

Kegunaan dan penggunaan tumbuhan ubatan adalah unik dan istimewa bagi setiap masyarakat. Kearifan tempatan berkaitan penggunaan tumbuhan sebagai ubat sangat penting dalam masyarakat Bugis sehingga ke hari ini. Amalan dan penggunaan tumbuhan ubatan untuk tujuan kesihatan dan kecantikan oleh wanita Bugis memerlukan lebih banyak kajian bukan sahaja untuk didokumentasikan tetapi untuk menjadi panduan kepada generasi akan datang serta kelangsungan amalan budaya tersebut dalam masyarakatnya.

\section{Rujukan}

Andi Nurela .(2012). Strategi Kelangsungan Hidup Masyarakat Perbatasan (Kasus Kondisi Sosial Ekonomi Masyarakat di Desa Aji Kuning Kecamatan Sebatik Tengah Kabupaten Nunukan Kalimantan Timur). Tesis Pasca Sarjana. Universitas Hasanuddin Makassar.

Andi Nurela, Maria Pandu \& Syaifullah Cangara. (2012). Strategi Kelangsungan Hidup Masyarakat Perbatasan. Jurnal Analisis, 1(1), 73-77.

Dloyana Kusumah. (2017). Pengobatan Tradisional Orang Bugis-Makassar. Jurnal Patanjala, 9(2), $245-260$

Jacinta Tangil dan Asmiaty Amat. (2020). Local Wisdom in the Bombon System by the Kadazandusun Society in Kiulu, Tuaran, Sabah. Malaysian Journal of Social Sciences and Humanities (MJSSH), 5(2), 77- 86. https://msocialsciences.com/index.php/mjssh/article/view/365. [8/4/2020].

Jurry Foo dan Kadir bin Jaafar. (2017). Faktor yang Mempengaruhi Sikap Mengenai Tumbuhan Ubatan dari Perspektif Sosiobudaya. International Journal of Society, Development and Environment in the Developing World.

Jurry Foo, Mustafa Omar, Ahmad Aldrie Amir \& Latiff, A. (2014). Faktor kelangsungan pasaran tumbuhan ubatan di tamu di pantai barat Sabah: Satu tinjauan awal. GEOGRAFIA OnlineTM Malaysian Journal of Society and Space, 10(2), 147-160.

Kanta Kumari, Dan Yit May \& Tuan Marina Tuan Ibrahim (1998) Economic Significance Of Medicinal Plants In Peninsular Malaysia. Kuala Lumpur: Jabatan Perhuhatan Semenanjung Malaysia.

Minah Sintian. 2019. Nilai-nilai Kearifan Lokal dalam Cerita Rakyat Kadazandusun. Dlm. Kesusasteraan \& Kebudayaan Borneo. Edisi 1. Tg. Malim. Penerbit Universiti Pendidikan Sultan Idris. $\quad$ https://www.researchgate.net/publication/333601492_Nilainilai_Kearifan_Lokal_dalam_Cerita_Rakyat_Kadazandusun [12/4/2020].

Robert Siburian (2012). Pulau Sebatik: Kawasan Perbatasan Indonesia Beraroma Malaysia. Jurnal Masyarakat \& Budaya, 14(1).

Suriyanah Laude \& Jurry Foo (2019). Penggunaan Tumbuhan Ubatan Di Kampung Aji Kuning, Sebatik Sabah. Kertas kerja Prosiding. Seminar Kebangsaan Pascasiswazah Sains Sosial dan Kemanusiaan (SPSSK 2019). Kota Kinabalu, Sabah. 